\title{
Determining Ovarian Maturity in Farmed Sturgeon 1 (Acipenser transmontanus) for Caviar Production Using Fourier Transform Infrared Spectroscopy (FT-IR)
}

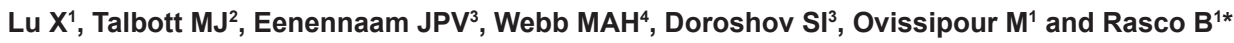 \\ ${ }^{1}$ School of Food Science, Washington State University, Pullman, WA 99164-6376, USA \\ ${ }^{2}$ Montana Cooperative Fishery Research Unit, Montana State University, Bozeman, MT 59717, USA \\ ${ }^{3}$ Department of Animal Science, One Shields Avenue, University of California, Davis, CA 95616, USA \\ ${ }^{4}$ Bozeman Fish Technology Center, U.S. Fish and Wildlife Service, 4050 Bridger Canyon Rd, Bozeman, MT 59715, USA
}

\begin{abstract}
Ovarian maturity of white sturgeon (Acipenser transmontanus, Acipenseridae) farmed in California (Sterling Caviar, LLC) $(\mathrm{N}=400)$ and Idaho (Fish Breeders and Blind Canyon Aqua Ranch) $(\mathrm{N}=143)$ was determined by correlating blood plasma spectral features [(Fourier transform infrared (FT-IR, 4000-400 $\mathrm{cm}^{-1}$ ) spectroscopy] with oocyte polarization index (PI), an index of germinal vesicle migration. A total of $\sim 20,000$ spectra were collected over a period of four years $(2007,2008,2009$ and 2010). Mathematical models could predict maturity in fish at a later year of harvest (i.e., 2010) and at either the California or Idaho production sites. PI values of $0.10,0.15$, and 0.20 were selected for segregating fish into subgroups based on ovarian maturity. Spectral features for specific proteins, lipids, carbohydrates and nucleic acids were related to fish maturity stages. Mathematical models could predict the actual PI values based on plasma spectral features in fish from 2010 based on models developed and validated from fish harvested in 2007-2009. These models worked equally well whether the fish were raised in California or Idaho. This research indicates that infrared spectroscopy provides a rapid and less invasive method to segregate sturgeon females according to maturity levels and has the potential to substitute for the traditional surgical biopsy to determine stage of maturity.
\end{abstract}

Keywords: Sturgeon; Caviar; Infrared spectroscopy; Chemo metrics

\section{Introduction}

Sturgeon brood stock management in aquaculture and in conservation programs for endangered species will benefit from the improved staging of fish by maturity. Accurately predicting maturity is also commercially important in aquaculture and stock management if a uniform and consistent egg size and firmness are to be obtained and caviar yields are to be optimized [1-3]. Optimizing harvest time could extend the caviar production season.

Currently, the only means to assess ripeness of white sturgeon (Acipenser transmontanus, Acipenseridae) females and the proper time of harvest is measurement of oocyte polarization index (PI) requiring a surgical biopsy. Oocyte PI is a ratio of the distance of the germinal vesicle from the animal pole to the oocyte animal-vegetal axis diameter [4]. PI indicates morphogenetic changes in the ovarian follicle occurring during late vitellogenesis and leading to maturational competence. This technique is accurate but invasive and stressful, time consuming, and not an effective tool for handling a large number of fish. When applied repeatedly, surgical biopsy often results in decreasing caviar yield and quality due to ovarian follicular atresia, the phagocytosis of ovarian eggs [2]. Females undergoing the first stage of atresia may appear to be normal at harvest; but once processed, the caviar may have to be downgraded due to egg softness and its yield severely diminished due to the loss of eggs bursting during processing and handling [5]. Even the early stage of atresia causes a reduction in the firmness, flavor, and shelf life of caviar.

To improve harvest prediction, we need to have a better understanding of the biochemical and physiological changes during ovarian maturation and how these changes correlate with roe quality. We also need new methods to predict sturgeon maturity as an alternative to the ovarian biopsy and oocyte PI measurement. New methods should be less invasive, preferably non-invasive and minimally stressful to fish, and quick. Ideally, they would allow female fish to be sorted in the fall segregating the fish that are in late vitellogenesis from other fish based upon the degree of ripeness so that fish 65 of the appropriate stage of maturity can be harvested during the winter and spring.

Infrared spectroscopy provides a unique advantage of simple sample preparation while retaining satisfactory precision and sensitivity. It is gaining wider use in chemical analysis and in nondestructive applications. In our previous work, Fourier transform infrared (FT-IR) spectroscopy $\left(4000-400 \mathrm{~cm}^{-1}\right)$ was employed to investigate the biochemical composition of sturgeon plasma [6] and the spectral features could be partially related to sturgeon reproductive maturity at different stages [7]. Other research indicates that sex steroids and vitellogenin (VTG) in sturgeon blood plasma serve as suitable biomarkers for predicting sturgeon maturity [8-11]. Spectra reflect important chemical information in plasma, including proteins, lipids, polysaccharides, nucleic acids, and constituents important for fish reproduction, such as vitellogenin (VTG) and sex steroids. The raw FT-IR spectral features of white sturgeon plasma were characterized in earlier studies $[6,7]$. The relationship between an ovarian histological

*Corresponding author: Barbara Rasco, School of Food Science, Washington State University, P.O. Box 646376, Pullman, Washington 99164-6376, USA, Tel: +1-509-335-1858; Fax: +1-509-335-4815; E-mail: rasco@wsu.edu

Received September 09, 2013; Accepted October 28, 2013; Published November 16, 2013

Citation: Lu X, Talbott MJ, Eenennaam JPV, Webb MAH, Doroshov SI, et al. (2013) Determining Ovarian Maturity in Farmed Sturgeon 1 (Acipenser transmontanus) for Caviar Production Using Fourier Transform Infrared Spectroscopy (FT-IR). J Aquac Res Development 5: 202 doi:10.4172/2155-9546.1000202

Copyright: @ 2013 Lu X, et al. This is an open-access article distributed under the terms of the Creative Commons Attribution License, which permits unrestricted use, distribution, and reproduction in any medium, provided the original author and source are credited. 

transmontanus) for Caviar Production Using Fourier Transform Infrared Spectroscopy (FT-IR). J Aquac Res Development 5: 202 doi:10.4172/2155-9546.1000202

prediction of sturgeon maturity and the concentration of biochemical compounds in plasma can also be determined [10]. The major focus of this study was to describe the biochemical characterization of sturgeon plasma and caviar. The aim in the current study was to establish that reliable chemometric models could be developed for field application at different production locations (in this case 2 states (California and Idaho) in which the culture conditions for the fish were significantly different) and across several harvest years. The significance of this work was to lop robust prediction that could be used at multiple harvest locations and from year to year. Therefore, it would be best to incorporate as many samples as possible into the study, creating some overlap. Due to this, current study presents the prediction models of oocyte PI from plasma spectral features from 543 female sturgeon harvested over a four year period to provide a new means to monitor sturgeon maturity.

\section{Materials and Methods}

\section{Field studies and sample preparation}

The sampling protocol is shown in Table 1.

Period I: (Fall 2007-Spring 2008): During the first year, fish were selected and harvested at Sterling Caviar LLC (Wilton, CA, USA), a farm with a large stock of mature fish and well known chronology of the sturgeon ovarian cycle. Here, we developed and refined diagnostic tools that were during the remaining three years of the study. Egg and blood plasma samples and spectra were repeatedly collected from the same group of individually tagged female fish and information on morphological and biochemical changes occurring as these fish matured were collected exploring the potential of segregating latevitellogenic fish into classes of maturity for an extended caviar harvest.

Forty randomly selected fish in the late vitellogenic stage were harvested at 2 month intervals (for Period I: September 2007; January, March and May 2008) for caviar production. At each sampling, ovarian biopsies were performed to measure the oocyte PI and assess the stage of oocyte development as previously described $[6,12]$. During biopsy, blood was collected from the caudal vasculature and centrifuged. Blood plasma (3.5 $\mathrm{ml}$ for each fish) was shipped frozen by overnight courier to Washington State University, Pullman, WA, USA for FT-IR spectral analysis.

Period II: (Fall 2008-Summer 2009): During the second year of the study, we explored protocols for segregation of fish by stage of maturity for the purpose of extending the harvest season in California and evaluation of diagnostic techniques. In November, we collected blood

\begin{tabular}{|c|c|c|c|c|}
\hline \multirow{3}{*}{\begin{tabular}{|l|} 
Time Period \\
Period I (2007-2008 \\
\end{tabular}} & \multicolumn{4}{|c|}{ Harvest location and Number of Fish } \\
\hline & \multicolumn{2}{|c|}{ California } & \multicolumn{2}{|c|}{ Idaho } \\
\hline & 40 (Sept 07) & 40 (Jan 08) & 40 (Mar 08) & 40 (May 08) \\
\hline $\begin{array}{l}\text { Period II* } \\
(2008-2009) \\
\text { Initial Sampling } \\
\text { Subsequent } \\
\text { Sampling }\end{array}$ & $\begin{array}{l}120 \text { (Nov 08) } \\
30 \text { (Jan 09) } \\
30 \text { (Mar 09) } \\
30 \text { (May 09) } \\
30 \text { (June 09) }\end{array}$ & & $\begin{array}{l}10 \times 2(\text { Nov 08) } \\
10 \times 2(\text { Jan 09) } \\
10(\text { Nov 09) }\end{array}$ & $\begin{array}{l}10 \times 2 \text { (Mar 09) } \\
10 \times 2 \text { (May 09) } \\
10 \times 2 \text { (Aug 09) } \\
10(\text { Jan } 10) \\
10(\text { Mar } 10) \\
10 \text { (May 10) } \\
10 \text { (Aug 10) }\end{array}$ \\
\hline $\begin{array}{l}\text { Period III } \\
(2009-2010) \\
\text { Initial Sampling } \\
\text { Subsequent Sam- } \\
\text { pling }\end{array}$ & $\begin{array}{l}30 \text { (Jan 10) } \\
30 \text { (Mar 10) } \\
30 \text { (May 10) } \\
30 \text { (June 10) }\end{array}$ & & & \\
\hline
\end{tabular}

Table 1: Sturgeon selected for analysis by sampling period and harvest location. and egg samples from randomly selected females at Sterling Caviar, LLC and segregated these fish into subgroups based upon maturity, e.g. pre-vitellogenesis, post-vitellogenesis, and atretic as determined by PI value. Individuals in these subgroups were individually tagged and held at the cold water facility from November to June, with the harvest of these fish conducted in January, March, May and June when fish were determined to 6be mature and at this point sacrificed for caviar production. The harvest interval 111 between subgroups may have shifted depending upon the sexual maturity results at segregation and modified depending upon optimal yield based upon data from fish in Period I. In November 2008 and again in January, March, May, and August 2009, 10 sturgeon were selected at random from two different locations in Idaho for testing namely Fish Breeders of Idaho and Blind Canyon Aqua Ranch (Hagerman, ID, USA). Tissue samples were collected and analyzed as described above. Seven out of these one hundred fish died after ovarian biopsies during Period II. Collection of biological samples and measurements from randomly selected sturgeon females from November through August provided a wide range of the oocyte PI values to be captured throughout the harvest season. Farmers provided information on annual temperature regimes and fish age and size in these cohorts. Biochemical and morphometry characteristics were compared between Idaho and California fish to determine maturity in sturgeon exposed to the different environmental conditions at the different production locations.

Period III: (Fall 2009-Summer 2010): The biological samples and spectra collected during Period I and II of the study provided information regarding the morphological and biochemical changes associated with maturity. FT-IR spectroscopic methods were evaluated during Period III at both California and Idaho farms. The validity of these various calibrations models has been previously described [6,7]. The original model for predicting maturity developed for fish during Period I and II was used in November 2009 by culturists to select 120 fish from California and 50 fish from Idaho into maturity classes based upon an FT-IR model for prediction of oocyte PI instead of actual measured oocyte PI. These fish were harvested for caviar at the predicted optimal stage of oogenesis, i.e., full-grown oocytes during January to August 2010, with selected results presented in Table S1.

\section{PI determination}

The ovarian follicle diameter was measured for 15 follicles per fish (Leica 134 DM 2000, $2.5 x$, RT SE Spot camera). These follicles were then bisected along the animal-vegetal axis for measurement of oocyte PI by image analysis. Oocyte PI, a measure of stage of maturation, is the ratio of the distance of the nucleus from the animal pole to the oocyte diameter (Figure 1). Follicles designated for histological analysis were processed by dehydration, embedding in paraffin, sectioning at $5 \mu \mathrm{m}$, and staining using periodic acid-Schiff's solution, hematoxylin and eosin.

\section{Plasma analysis by FT-IR spectroscopy}

Twenty microliters of the plasma was applied to a glass slide and air dried under laminar flow at room temperature (ca. $22^{\circ} \mathrm{C}$ ) for 1 $\mathrm{h}$ to obtain a uniform dry film. Three slides were prepared for each plasma sample. FT-IR spectra were collected using a Thermo Nicolet 360 FT-IR spectrometer (Thermo Electron Inc., San Jose, CA, USA). Glass slides with dried plasma spots were placed in direct contact with an attenuated total reflectance (ATR) zinc selenide (ZnSe) crystal and spectra taken (4002 to $399 \mathrm{~cm}^{-1}$ ). The wave numbers between 3200 to $2800 \mathrm{~cm}^{-1}$ and 1800 to $900 \mathrm{~cm}^{-1}$ were selected for all chemo metric analyses in this study. Thirty spectra were collected for each plasma 
Citation: Lu X, Talbott MJ, Eenennaam JPV, Webb MAH, Doroshov SI, et al. (2013) Determining Ovarian Maturity in Farmed Sturgeon 1 (Acipenser transmontanus) for Caviar Production Using Fourier Transform Infrared Spectroscopy (FT-IR). J Aquac Res Development 5: 202 doi:10.4172/2155-9546.1000202

Page 3 of 6

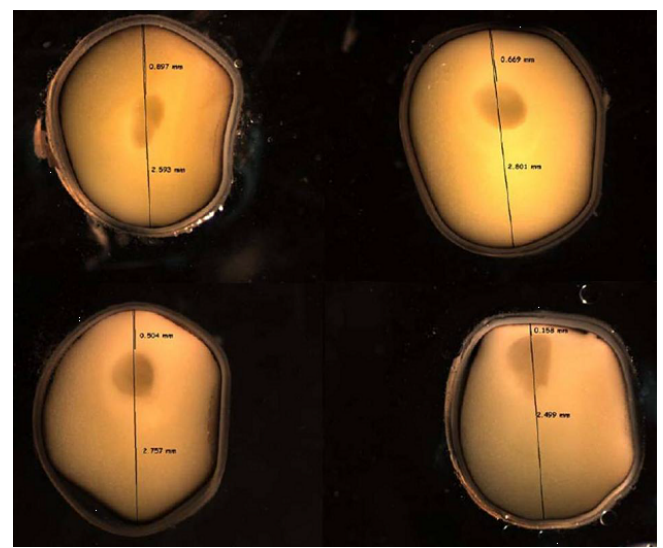

Figure 1: Photographs of sturgeon eggs for oocyte polarization index (PI) measurement (range from 0.063 to 0.346 ).

sample, ten for each slide. The resolution of the FT-IR spectroscopic instrument was set at $4 \mathrm{~cm}^{-1}$ with spectrum taken of a mean of 36 separate scans. This spectral collection method was conducted during Period I and II to establish models. However, for PI prediction, the sample preparation was somewhat different. Twenty micro liters of plasma was directly applied to crystal cell of spectrometer and dried with a fan within ten minutes. This change of sample preparation during Period III was aimed at shortening spectral collection time allowing for more rapid PI prediction after chemo metric models had been established. The differences between spectral intensity between these two methods could be converted using the formulas presented below so that spectra for PI prediction could be added into previously established models.

Band Intensity of Spectra glass slide=Peak Intensity of Spectra direct 157 applied/3.106

Band Area of Spectra glass slide=Peak Area of Spectra direct applied/4.762

The intensity and area of spectral bands were measured and calculated using OMNIC (Thermo Electron Inc. San Jose, CA, USA) and Origin ${ }^{\circledR} 1608.1$ (OriginLab Co., Northampton, MA, USA) software packages, with the principles for these analytical methods as described $[13,14]$. Either equation presented above could be successfully applied for spectral data conversion for PI prediction models.

\section{Spectral processing and chemometrics}

FT-IR spectral analyses were conducted using OMNIC and Matlab software (The Math Works, Inc., Natick, MA, USA). The steps involved in spectra processing included smoothing (using a Gaussian function of $9.463 \mathrm{~cm}^{-1}$ ), automatic baseline correction, normalization, second derivative transforms (with a gap value of $10 \mathrm{~cm}^{-1}$ ) and wavelet transforms (with a scale of 7) [15]. The reproducibility of the processed FT-IR spectra (Table 2) were evaluated by calculating $D_{\text {yly2 }}$ [6]. After data pre-processing as described above, chemometric models were established to segregate sturgeon into PI sub-groups based upon spectral features. These models including cluster analysis, Principal Component Analysis (PCA), dendrogram analysis, class analog analysis (SIMCA) and loading plot analysis to show that the models constructed for segregation were both valid and stable, a Bayesian probability analysis was developed and the stability of the model was determined by using a Monte Carlo estimation as described previously [16]. To establish a correlation between spectral features and PI, partial least squares regression (PLSR) models were developed. In these models, the measured oocyte PI values for each fish served as reference values. To determine how robust a PLSR model is, the number of latent variables, correlation coefficient (R), standard error and outlier diagnostics need to be determined [17]. After a PLSR calibration model is established, it is validated by cross validation using plasma samples from either 9 the same data set that were not used for model construction or with plasma samples 180 from new data sets.

A validated calibration model could then be employed to predict oocyte PI for other fish.

\section{Results}

\section{Determining spectral reproducibility}

The reproducibility of FT-IR spectra from three independent experiments were calculated using the Pearson coefficient (expressed as $D_{\text {y1y } 2}$ value). Here the $D_{\text {y1y2 }}$ value of FT-IR spectra for specific wavenumber regions are presented along with a combination of wavelength regions [16] (Table 2). Mean $D_{\mathrm{yly2}}$ values between 7 and 10 are considered to be normal [7]

\section{Segregating sturgeon by sexual maturity based upon spectral analyses}

Sturgeon of different maturity were clearly segregated from each other $(P<0.05)$ through a correlation of spectral features with PI values

\begin{tabular}{|l|l|l|}
\hline Wavenumber $\left(\mathbf{c m}^{-1}\right)$ & Biochemical constituents & $\begin{array}{l}\boldsymbol{D}_{\text {y1y2 }} \text { values for } \\
\text { corresponding }\end{array}$ \\
\hline wavenumber regions & & \\
\hline $3300-900$ & Entire wavenumber region & $16.12 \pm 3.82$ to $24.13 \pm 2.91$ \\
\hline $3200-2800$ & Fatty acids & $8.34 \pm 0.17$ to $8.91 \pm 0.21$ \\
\hline $1800-1500$ & Proteins and peptides & $7.11 \pm 0.39$ to $8.56 \pm 0.48$ \\
\hline $1500-1200$ & $\begin{array}{l}\text { Mixed region of proteins, } \\
\text { fatty acids and }\end{array}$ & \\
\hline phosphate compounds & $7.46 \pm 0.31$ to $8.81 \pm 0.69$ & \\
\hline $1200-900$ & Carbohydrate & $9.01 \pm 0.23$ to $9.89 \pm 0.45$ \\
\hline
\end{tabular}

Table 2: Determining FT-IR spectral reproducibility based upon important plasma biochemical constituents.

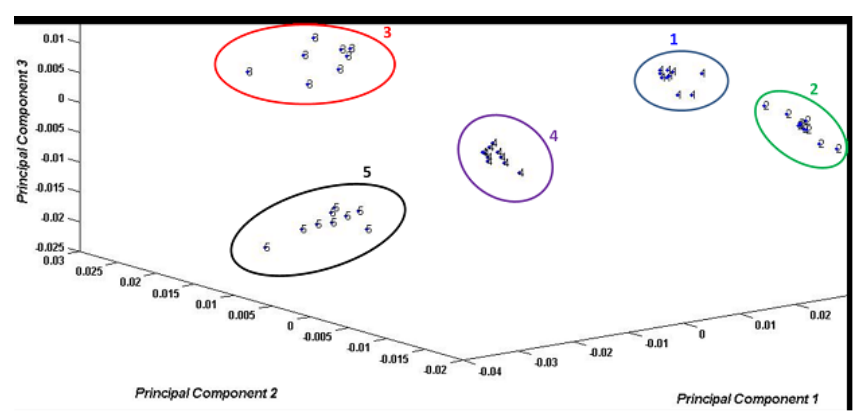

Figure 2: Principal Component Analysis for PI values of sturgeon. Fish were sorted into different maturity levels using the following groupings: group 1: $0.05<\mathrm{PI}<0.10$; group 2: $0.10<\mathrm{PI}<0.15$; group 3 : $0.15<\mathrm{PI}<0.20$; group 4: $0.20<\mathrm{Pl}<0.25$; group 5: $\mathrm{Pl}>0.25$. In this three-dimensional (3D) unsupervised PCA model, each point represents one sturgeon plasma sample (average spectra $(\mathrm{N}=30)$ ) randomly selected from both Idaho and California fish during Period I and II (2007-2009). This cluster analysis model was validated by using fish collected in 2010 from California and is a representative of one of the ten models developed $(\mathrm{N}=10)$. Each maturity level group was well separated $(P<0.05)$ and tightly clustered with interclass distances ranging from 6.49 to 21.64 based on Mahalanobis distance measurements computed between the centroids of the clusters. A Mahalanobis distance of $>3$ indicates good segregation [18] 

transmontanus) for Caviar Production Using Fourier Transform Infrared Spectroscopy (FT-IR). J Aquac Res Development 5: 202 doi:10.4172/2155-9546.1000202

(Figure 2) and could be differentiated into PI ranges or groupings commonly used in the industry for segregating fish. As others have found for two-dimensional (2D) cluster analyses it was not possible to clearly segregate fish by maturity a common phenomenon observed with biological samples [18,19] and a 3-dimensional (3D) model was necessary to discern small changes in spectral features between fish with similar PI. This model (Figure 2) was established using 7and 8-year old fish in California and 15- to 21-year old fish in Idaho sampled over three years (Period I and II) and validated using fish of sampled during Period III ( $N=52)$. A dendrogram analysis, also based upon principal components was established to segregate sturgeon based upon different maturity levels (oocyte PI ranges) (Figure 3) also using fish from Period I and II and validated with fish from Period III. Fish with low PI values of 0.05 or 0.1 could be easily segregated 10from fish with higher PIs $(0.15,0.2$ or 0.25$)$ using a single principal component (PC 1). This model may be more robust than the 3D PCA (Figure 2) because only a single principal component was necessary for its construction. It was possible to validate oocyte PI values of 0.05 , $0.1,0.15,0.20$ and 0.25 as critical points for segregating sturgeon with PI values of $0.1,0.15$ and 0.20 . Many combinations of segregation models were evaluated during model establishment and we confirmed that the dendrogram model presented here (Figure 3 ) could provide the best segregation of the dendrogram analysis models tested. A third type of model for segregating fish based upon spectral features was a class analog or SIMCA model. This model can be used to determine if a certain fish, based upon its blood plasma spectral features would fall within a predetermined range of PI values. Using this model, fish could be correctly classified $90 \%$ of the time based on plasma spectral features alone (Table 3).

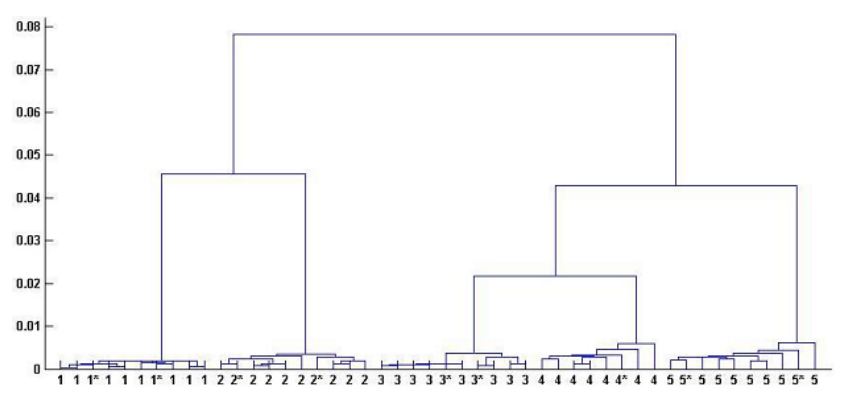

Figure 3: A composite dendrogram for hierarchical cluster analysis of predicted PI Fish were sorted into different maturity levels using the following groupings: group 1: $0.05<\mathrm{PI}<0.10$; group 2: $0.10<\mathrm{PI}<0.15$; group 3: $0.15<\mathrm{PI}<0.20$; group 4: $0.20<\mathrm{PI}<0.25$; group 5: $\mathrm{Pl}>0.2)$. Each number on the $\mathrm{x}$-axis represents one sturgeon blood plasma (average spectra $(\mathrm{N}=30)$ ) randomly selected both Idaho and California during Period I and II (2007-2009). This segregation analysis model is representative of one of the ten models validated by using fish samples from 2010 from California ( $N=10)$. An asterisk marks a sample used for mode validation and subsequent validation challenge.

\begin{tabular}{|l|l|l|}
\hline PI Range & $\begin{array}{l}\text { No. of correctly } \\
\text { classified spectra* }\end{array}$ & $\begin{array}{l}\text { \% of correctly classified } \\
\text { spectra }\end{array}$ \\
\hline $0.05<\mathrm{PI}<0.10$ & 278 & 92.67 \\
\hline $0.10<\mathrm{PI}<0.15$ & 281 & 93.67 \\
\hline $0.15<\mathrm{PI}<0.20$ & 269 & 89.67 \\
\hline $0.20<\mathrm{PI}<0.25$ & 271 & 90.33 \\
\hline $\mathrm{PI}>0.25$ & 292 & 97.33 \\
\hline
\end{tabular}

*Note: $\mathrm{N}=300$ spectra from fish in each $\mathrm{PI}$ range

Table 3: SIMCA classification accuracy for different ooc yte polarization index (PI) ranges.

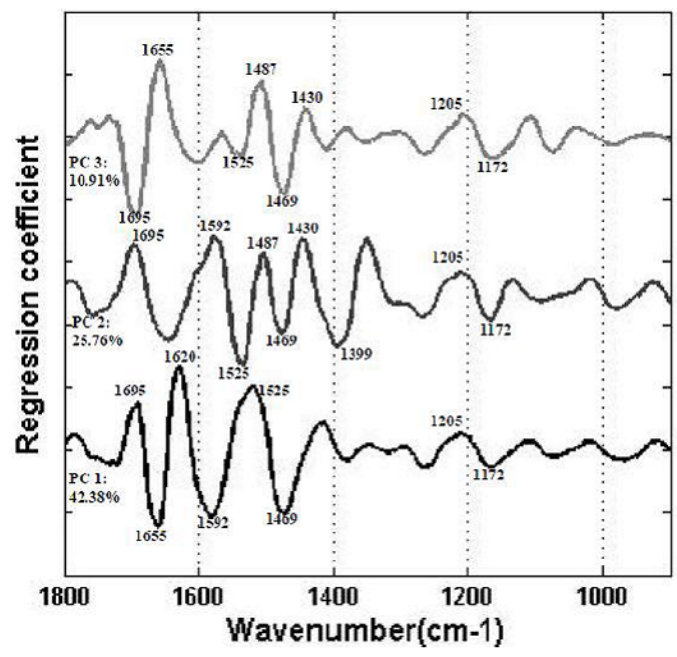

Figure 4: Loading plots to explain cluster analysis and dendrogram analysis. Band assignment, $1695 \mathrm{~cm}^{-1}$ : amide I band component; $1655 \mathrm{~cm}^{-1}$ : amide I of $\alpha$-helical structures; $1620 \mathrm{~cm}^{-1}$ : stretching base carbonyl and ring breathing mode of nucleic acid; $1592 \mathrm{~cm}^{-1}: \mathrm{C}=\mathrm{N}, \mathrm{NH} 2$ adenine; $1525 \mathrm{~cm}^{-1}$ : amide II (15501515); $1487 \mathrm{~cm}^{-1}$ : C=C, deformation $\mathrm{C}-\mathrm{H}$ of amide II; $1469 \mathrm{~cm}^{-1}: \mathrm{CH} 2$ bending of the acyl chains (phospholipids); $1430 \mathrm{~cm}^{-1}: \delta(\mathrm{CH} 2)$ of polysaccharide; 1399 $\mathrm{cm}^{-1}$ : symmetric $\mathrm{CH} 3$ bending modes of the methyl groups of proteins; 1205 $\mathrm{cm}^{-1}$ : C-O-C, C-O dominated by the ring vibrations of polysaccharides C-O-P, P-O-P; $1172 / 1173 \mathrm{~cm}^{-1}$ : CO stretching of the $\mathrm{C}-\mathrm{OH}$ groups of serine, threonine, \& tyrosine in the cell proteins as well as carbohydrates.

\section{Loading plot analysis}

Loading plot analysis was performed to determine which major components in plasma provided the most significant $(P<0.05)$ contribution to sample segregation (Figure 4). The first three PCs can explain over $80 \%$ of segregation capability of either the cluster or dendrogram models (Figures 2 and 3 ) with the most significant features being associated with changes to protein secondary structure: amide I $\left(1695 \mathrm{~cm}^{-1}\right)$ [7,20,21]; $\alpha$-helical structures $\left(1655 \mathrm{~cm}^{-1}\right)$ [22]; amide II $\left(1525 \mathrm{~cm}^{-1}\right)$ [19]; C=C, deformation C-H of amide II (1487 $\mathrm{cm}^{-1}$ ) [22]; symmetric $\mathrm{CH} 3$ bending modes of the methyl groups of proteins $\left(1399 \mathrm{~cm}^{-1}\right)$ [19]; CO stretching of the C-OH groups of serine, threonine and tyrosine in the cell proteins $\left(1172 / 1173 \mathrm{~cm}^{-1}\right)$ [19]. For carbohydrate, the band at $1430 \mathrm{~cm}^{-1}$ is assigned to $\delta(\mathrm{CH} 2)$ of polysaccharide $[7,20,21]$, while the band at $1205 \mathrm{~cm}^{-1}$ is dominated by the ring vibrations of polysaccharides C-O-P, PO-P [22]. The band at $1469 \mathrm{~cm}^{-1}$ is derived from $\mathrm{CH} 2$ banding of the acyl chains from phospholipids $[7,20,21]$. The band at $1620 \mathrm{~cm}^{-1}$ is assigned to stretching base carbonyl and ring breathing mode of 11 nucleic acids [19], and $1592 \mathrm{~cm}^{-1}$ is assigned to $\mathrm{C}=\mathrm{N}$ and NH2 in adenine [22]. These features are principally associated with protein and lipid deposition as ovarian follicles mature, with carbohydrate features likely associated with changes in levels of vitellogenin (VTG).

\section{Application of PLSR models for oocyte PI prediction}

PLSR models established a correlation between plasma spectral features and morphological characteristics of ovarian follicles. The appendix provides programming of the PLSR model in Matlab used for this chemometric analysis based on spectral features and includes calibration, cross validation and prediction (Appendix I). Two PLSR models were established (Figure 5, Tables 4 and S1): model A and model B. For model A, randomly selected fish sampled in 2007, 2008 and 2009 were used for model establishment. A leave-one-out cross validation was performed to challenge the rigorousness of calibrated model and 

transmontanus) for Caviar Production Using Fourier Transform Infrared Spectroscopy (FT-IR). J Aquac Res Development 5: 202 doi:10.4172/2155-9546.1000202

Page 5 of 6
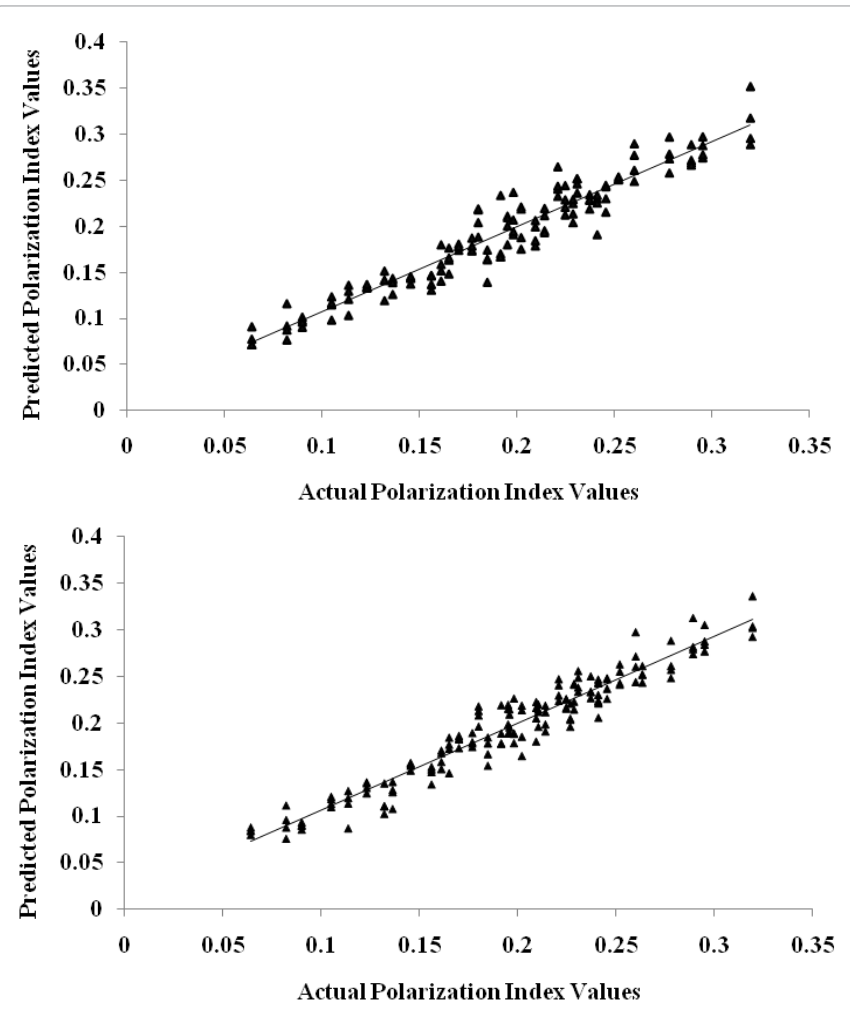

Figure 5: Partial least squares for linear regression analysis between actua $\mathrm{PI}$ values (measured by traditional surgical biopsy) $(\mathrm{N}=15)$ and predicted $\mathrm{P}$ values (FT-IR spectral features): model A (above) and model B (below). This PLSR model is a representative of one of the ten models developed as part of this study.

\begin{tabular}{|l|l|l|l|l|l|l|l|}
\hline $\begin{array}{l}\text { PI } \\
\text { model }\end{array}$ & Range & $\begin{array}{l}\text { No. of } \\
\text { Samples* }\end{array}$ & $\begin{array}{l}\text { No. } \\
\text { Latent } \\
\text { Variables }\end{array}$ & R-Val & SECV & R-Cal & SEC \\
\hline Model A & $0.0640-0.3195$ & 140 & 14 & 0.8725 & 0.0217 & 0.9227 & 0.0173 \\
\hline Model B & $0.0640-0.3195$ & 160 & 17 & 0.8846 & 0.0129 & 0.9312 & 0.0107 \\
\hline
\end{tabular}

*Four spectra for each fish plasma sample were incorporated into the PLSR model

Table 4: Statistical parameters for Partial Least Squares Regression Models (PLSR) (1800 to $900 \mathrm{~cm}^{-1}$ ) for determination of polarization index values of white sturgeon eggs.

then the PI values of fish samples collected in 2010 were predicted based upon the validated calibration model (Figure 5 model A, a prediction model). For a second model (model B, a cross-validation model), fish from Period I and II and 5 fish from Period III were randomly selected and used for model establishment and leave-one-out cross validation was performed to challenge the rigor of this calibration model. The PI values of all remaining fish collected during Period III were predicte based upon the validated calibration model (Figure 5 model B) with the accuracy of these predictions shown in Table S1.

The key parameters of PLSR models are summarized in Table 4, including range, number of samples, latent variables, standard error of calibration and cross validation, and regression coefficient of calibration and cross validation. PLSR model B provided a higher correlation than model A due to a greater incorporation of spectral features for fish collected in 2010. The prediction results for both PLSR models are summarized in Table S1. The standard deviation for model $\mathrm{A}$ is 0.03 and relatively small for an oocyte PI reference value around 0.2 or 0.3 , but relatively high for PI around $0.1(\sim 30 \%)$ which is a 12 critical value for harvest quality as a prediction of pre-ovulatory follicular atresia. 249 The standard deviation of model B is close to 0.01 , which is suitable even if the reference PI value is around 0.1 (Tables 4 and S1). Taken together, the models were equally applicable to unrelated white sturgeon stocks raised at two separate locations, California and Idaho, under different environmental conditions.

\section{Discussion}

Research has been conducted to investigate the reproductive physiology of sturgeon due in part to conservation and restoration activities for threatened and endangered species but also in support of efforts to improve aquaculture practices for these fish. International demand for sturgeon caviar is focusing attention of scientists on improvement to sturgeon aquaculture that has recently become a major source for caviar production [23].

White sturgeon (native to Washington, Oregon, California and Idaho in the United States and to the province of British Columbia in Canada) [24] are with biennial ovarian cycles starting in captivity at age 5-7 years. The phases of the ovarian cycle have been determined histologically and through plasma metabolic profiles [10]. Because of the asynchronous onset of vitellogenesis and its long duration, the maturing stocks will typically have three main ovarian stages if sampled in the fall [25]. Currently, measuring the oocyte PI value is the only means to accurately assess ripeness of white sturgeon females. It is better to select females with the PI scores of less than 0.10 for spawning induction, although an egg polarization index of 0.06-0.08 is preferable [26].

Besides measuring PI values, hormone levels in fish plasma have also been used to determine sturgeon maturity levels. Moberg et al. [27] indicated that plasma concentrations of estradiol-17 $\beta$ (E2) can discriminate the vitellogenic stage in sturgeon. Webb et al. $[28,29]$ reported that plasma testosterone $(\mathrm{T})$ and $\mathrm{E} 2$ were the best predictors to differentiate sex and stages of maturity in white sturgeon. Malekzadeh Viayeh et al. [30] showed that plasma T and E2 plus either age, total length, 272 fork length or weight were also good predictors for the stage of sturgeon sexual maturity. The most viable methods for quantifying sex steroid contents in fish plasma are radioimmunoassay (RIA) [12] and enzyme-linked immunosorbent assay (ELISA) [31]. The techniques developed here, provide culturists with models that can be used to predict PI value for the fish from PLSR models developed on the basis of 20,000 FT-IR spectra from a 4-year cumulative study of 543 sturgeon females farmed in both California and Idaho. This method would be appropriate for conservation and restoration efforts in addition to aquaculture been rapidly developed, increasing the field applicability of this technology [32].

All species of sturgeon are very sensitive to environmental conditions on spawning grounds, such as seasonal temperature, river velocity, and availability of specific spawning substrate. Our spectroscopic method has a potential application for monitoring the stage of the egg maturity and potentially the incidence of pre-ovulatory follicular atresia in natural spawning populations, such as the recently re-established spawning runs of lake sturgeon and the endangered stock of the Kootenai River white sturgeon. These populations, while being protected, may still be at risk due to the changes in the river thermal regime and the high sensitivity of sturgeon spawning to temperature, spawning substrate, and current velocity [4]. A rapid and minimally invasive spectroscopic method such as the ones presented here would provide a unique opportunity for monitoring reproductive health of the brood fish that are on or near natural spawning grounds. It will 
Citation: Lu X, Talbott MJ, Eenennaam JPV, Webb MAH, Doroshov SI, et al. (2013) Determining Ovarian Maturity in Farmed Sturgeon 1 (Acipenser transmontanus) for Caviar Production Using Fourier Transform Infrared Spectroscopy (FT-IR). J Aquac Res Development 5: 202 doi:10.4172/2155-9546.1000202

Page 6 of 6

also permit the determination of the potential impact of pre-ovulatory ovarian follicular atresia, and provide a new tool for predicting the impact of environmental changes on sturgeon populations and may have applications for rapid determination of reproductive status in cobia, barramundi and potentially tunas.

\section{Acknowledgements}

This study was funded by a grant from the Western Regional Aquaculture Center, U.S. Department of Agriculture, under grant number 2007-38500-18593 Special thanks to Linda and Gary Lemmon, Blind Canyon Aqua Ranch, Inc., Leo Ray, Fish Breeders of Idaho, Inc., and Peter Struffenegger, Sterling Caviar, LLC, and their staffs for raising the fish that provided the samples for this study.

\section{References}

1. Bledsoe GE, Bledsoe CD, Rasco B (2003) Caviars and Fish Roe Products. Crit Rev Food Sci 43: 317-356.

2. Webb MAH, Doroshov SI (2011) Importance of Environmental Endocrinology in Fisheries Management and Aquaculture of Sturgeons. Gen Comp Endocrinol 170: 313-321.

3. Hosseinzadeh M, Imanpoor MR, Nekoubin H (2012) Histology of Ovarian Development and Maturity Stages in The Wild Persian Sturgeon, Acipenser Persicus. J Aquac Res Develop

4. Dettlaff TA, Ginsburg AS, Schmalhausen OI, Gause GG, Vassetzky S (1993) Sturgeon Fishes: Developmental Biology and Aquaculture. Verlag, New York: Springer.

5. Webb MAH, Van Eenennaam JP, Doroshov SI, Moberg GP (1999) Preliminary Observations on The Effects of Holding Temperature on Reproductive Performance of Female White Sturgeon, Acipenser Transmontanus Richardson. Aquaculture 176: 315-329.

6. Lu X, Webb MAH, Talbott MJ, Van Eenennaam JP, Palumbo A, et al. (2010) Distinguishing Ovarian Maturity of Farmed White Sturgeon (Acipenser Transmontanus) by Fourier Transform Infrared Spectroscopy: A Potential Too for Caviar Production Management. J Agri Food Chem 58: 4056-4064.

7. Lu X, Webb MAH, Talbott MJ, Van Eenennaam JP, Doroshov SI, Et Al. (2011) A Study of Biochemical Parameters Associated With Ovarian Atresia and Quality of Caviar in Farmed White Sturgeon (Acipenser Transmontanus) by Fourier Transform Infrared (FT-IR) Spectroscopy. Aquaculture 315: 298-305.

8. Amiri BM, Maebayashi M, Hara A, Adachi S, Yamauchi K (1996) Ovarian Development 322 and Serum Sex Steroid and Vitellogenin Profiles in The Female Cultured Sturgeon Hybrid, The Bester. J Fish Biol 48: 1164-1178.

9. Bidwell CA, Carlson DM (1995) Characterization of Vitellogenin from White Sturgeon, Acipenser Transmontanus. J Molec Evol 41: 104-112.

10. Linares-Casenave J, Kroll KJ, Van Eenennaam JP, Doroshov SI (2003) Effect of Ovarian Stage on Plasma Vitellogenin and Calcium in Cultured White Sturgeon. Aquaculture 221: 645-656.

11. Talbott MJ, Van Eenennaam JP, Linares-Casenave J, Doroshov SI, Guy CS et al. (2011) Investigating the Use of Plasma Testosterone and Estradiol-17 Beta to Detect Ovarian Follicular Atresia in Farmed White Sturgeon, Acipenser Transmontanus. Aquaculture 315: 283-289.

12. Webb MA, Feist GW, Trant JM, Van Eenennaam JP, Fitzpatrick MS, Et AI (2002) Ovarian Steroidogenesis in White Sturgeon (Acipenser Transmontanus) During Oocyte Maturation and Induced Ovulation. Gen Comp Endo 129: 2738.

13. Darensbourg DJ, Tappan JE, Nelson HH (1977) Infrared Intensities and Calculation of Infrared Band Shapes of The .Nu. (Carbonyl) and .Nu. (Carbon:Carbon) Vibrational Modes In Group 6B (Norbornadiene) Tetracarbonylmetal Derivatives. Inorg Chem 16: 534-540.

14. Abdulov KS (2004) Calculation of the Band Intensities of the IR Spectra of Oriented Polymers. J Appl Spect 71: 487-492.

15. Bocklitz T, Walter A, Hartmann K, Rosch P, Popp J (2011) How To Pre-Process Raman Spectra for Reliable and Stable Models? Analytica Chimica Acta 704: 47-56.

16. Shreve J, Schneider H, Soysal O (2011) A Methodology for Comparing Classification Methods Through the Assessment of Model Stability and Validity in Variable Selection. Decis Support Syst 52: 247-257.
17. Alsberg BK, Kell DB, Goodacre R (1998) Variable Selection in Discriminant Partial Least-Squares Analysis. Anal Chem 70: 4126-4133.

18. De Maesschalck R, Jouan-Rimbaud D, Massart DL (2000) The Mahalanobis Distance. Chemo Intel Lab Sys 50: 1-18.

19. Naumann D (2001) FT-Infrared and FT-Raman Spectroscopy in Biomedical Research. Appl Spect Rev 36: 239-298.

20. Lu X, Rasco B, Kang DH, Jabal JM, Aston DE, et al. (2011) Infrared And Raman Spectroscopic Studies of The Antimicrobial Effects of Garlic Concentrates and Diallyl Constituents on Foodborne Pathogens. Anal Chem 83: 4137-4146.

21. Lu X, Al-Qadiri HM, Lin MS, Rasco B (2011) Application of Mid-Infrared and Raman Spectroscopy to the Study of Bacteria. Food Biopro Technol 4: 919 935.

22. Movasaghi Z, Rehman S, Rehman IU (2008) Fourier Transform Infrared (FTIR) Spectroscopy of Biological Tissues. Appl Spect Rev 43: 134-179.

23. Pourkazemi M (2006) Caspian Sea Sturgeon Conservation and Fisheries: Past Present and Future. J Appl Ichthyol 22: 12-16.

24. Bronzi P, Rosenthal H, Gessner J (2011) Global Sturgeon Aquaculture Production: An Overview. J Appl Ichthyol 27: 169-175.

25. Patino R, Yoshizaki G, Thomas P, Kagawa H (2001) Gonadotropic Contro of Ovarian Follicle Maturation: the Two-Stage Concept and its Mechanisms. Comp Biochem Physiol B-Biochem Molec Biolo 129: 427-439.

26. Chapman F, Van Eenennaam JP (2007) Sturgeon Aquaculture-Specialized Techniques: Determining The Stage of Sexual Maturity In Female Sturgeon for Artificial Spawning: The Egg Polarization Index or PI. Fisheries and Aquatic Sciences Department, Florida Cooperative 367 Extension Service, Institute of Food and Agricultural Sciences, University of Florida.

27. Moberg GP, Watson JG, Doroshov S, Papkoff H, Pavlick Jrrj (1995) Physiological Evidence for Two Sturgeon Gonadotrophins In Acipense Transmontanus. Aquaculture 135: 27-39.

28. Webb MAH, Van Eenennaam JP, Feist GW, Linares-Casenave J, Fitzpatrick MS, et al. (2001) Effects of Thermal Regime on Ovarian Maturation and Plasma Sex Steroids in Farmed White Sturgeon, Acipenser Transmontanus. Aquaculture 201: 137-151.

29. Webb MAH, Feist GW, Foster EP, Schreck CB, Fitzpatrick MS (2002) Potentia Classification of Sex and Stage of Gonadal Maturity of Wild White Sturgeon Using Blood Plasma Indicators. Trans Americ Fish Soc 131: 132-142.

30. Viayeh, RM, Webb M, Hallajian A, Kazemi R., Yali, MP, 2007. Biochemical and Morphometric Parameters as Indicators of Sex and Gonadal Stages in Maturing Persian Sturgeon, Acipenser Persicus. Journal of Applied Ichthyology 22: 364-368.

31. Nash JP, Cuisset BD, Bhattacharyya S, Suter HC, Le Menn F, Kime DE (2000) An Enzyme Linked Immunosorbant Assay (ELISA) for Testosterone, Estradiol and 17,20 Beta-Dihydroxy-4-Pregenen- 3-One Using Acetylcholinesterase As Tracer: Application To Measurement of Diel Patterns in Rainbow Trout (Oncorhynchus Mykiss). Fish Physiol Biochem 22: 355-363.

32. Mukhopadhyay R (2004) Product Review: Portable FTIR Spectrometers Get Moving. Anal Chem 76: 369A-372A 